\title{
A Concepção de Família de uma Mulher-Mãe de Vítimas de Incesto
}

\section{The Concept of Family from a Woman-Mother Victim of Incest}

\author{
Martha Giudice Narvaz*, Sílvia Helena Koller \\ Universidade Federal do Rio Grande do Sul, Porto Alegre, Brasil
}

\begin{abstract}
Resumo
O objetivo deste estudo foi o de investigar os discursos patriarcais inscritos nas concepões de família que têm sido mantidos ainda na atualidade. A participante do estudo foi uma mulher-mãe, vítima de violência na infância e na vida adulta, cujas filhas foram vítimas de incesto. O delineamento utilizado foi o estudo de caso, baseado em entrevistas semidirigidas. Os dados coletados foram submetidos à análise e discurso. Evidenciou-se a correspondência dos ditames patriarcais na concepção de família da participante. Mesmo não sendo o modelo efetivamente vivido, a concepção de família revelou a idealização do modelo hegemônico em nossa sociedade de família nuclear, monogâmica, patriarcal e burguesa. Uma vez que os dados foram coletados a partir de apenas um único caso, novas investigações são recomendadas. A investigação propõe-se a problematizar a hegemonia do modelo familiar patriarcal ainda prevalente em nossa sociedade, cujos ditames estão associados à dinâmica das famílias violentas e incestuosas.

Palavras-chave: Família; patriarcado; violência; gênero; discurso.
\end{abstract}

\begin{abstract}
The aim of this study was to explore the patriarchal discourses that are still presently registered in the concepts of family. The participant was a woman-mother, victim of violence during her childhood and adult life, whose daughters were victims of incest. The case study was based on semi-structured interviews. Discursive Analysis showed that patriarchal values correspond to the participant's concept of family. Her concept of family revealed to be an idealized nuclear, monogamy, patriarchal and bourgeois model of family, even though this model has not effectively been experienced by her. Since the data was obtained from only one case, new investigations are recommended. We intend to question the hegemonic patriarchal model of family that still endures in our society, whose imperatives have been associated to the dynamics of violent and incestuous families.

Keywords: Family; patriarchal; violence; gender; discourse.
\end{abstract}

O presente trabalho consiste em um estudo de caso de uma família incestuosa. O objetivo do estudo foi o de investigar a correspondência dos ditames patriarcais na concepção de família de uma mulher vítima de diversas formas de violência, da infância à vida adulta, cujas filhas foram vítimas de incesto. Partindo dos aportes da teoria crítica da família e dos estudos de gênero, encontramos na literatura importante correspondência das normas impostas pelos valores do patriarcado na constituição da família brasileira (Saffioti, 1979, 2001; Xavier, 1998). A concepção de família ainda prevalente em nosso meio corresponde ao modelo hegemônico de família nuclear, burguesa, monogâmica e patriarcal (Szymanski, 1992, 1994, 1997, 1998). A dinâmica das famílias incestuosas e a submissão das mulheres e

\footnotetext{
"Endereço para correspondência: Rua Ramiro Barcelos, 2600, 104, Porto Alegre, RS, 90035.003. Fones: (51) 39165150 , cel. (51) 81197091 ; Fax: (51) 32410074. E-mail: phoenx@terra.com.br e silvia.koller@gmail.com

Este artigo foi baseado na dissertação de Mestrado da primeira autora sob orientação da segunda autora. Agradecemos às integrantes da Equipe de Pesquisa, Júlia Bonjiovani e Lívia Zanchet, estudantes de graduação do Instituto de Psicologia da UFRGS, por suas contribuições neste estudo e à Iara, nome fictício da participante desta investigação.
}

das crianças às relações violentas aparece associada ao desejo de manterem a família unida (Cardoso, 1997a, 1997b). Tal compreensão parece-nos importante na medida em que pode subsidiar ações que visem à prevenção de relações familiares violentas, inclusive de incesto. A escolha do tema deve-se ao fato de ser o incesto um assunto polêmico, ainda tabu e pouco explorado pela literatura e pesquisas científicas. Daí a relevância do presente trabalho tanto em termos científicos quanto sociais.

Inicialmente, na revisão da literatura, são abordados temas tais como: as diferentes formas de organização familiar ao longo da história; as transformações dos papéis familiares na sociedade ao longo dos tempos; a constituição da família contemporânea brasileira; e, a relação das famílias violentas com os valores ditados pelo patriarcado. A seguir, são apresentamos, sucintamente, os dados coletados a partir das entrevistas realizadas, discutidos à luz do referencial teórico estudado. Nas considerações finais, algumas conclusões suscitadas a partir da presente investigação apontam para a problematização da hegemonia do modelo de família existente no imaginário social, cujos ditames parecem estar associados à dinâmica das relações familiares violentas e 
incestuosas. Algumas limitações deste estudo também são abordadas, sugerindo-se outros estudos sobre o tema.

\section{Revisão da Literatura}

Estudiosos da família (Canevacci, 1987; Engels, 1884/ 1964; Figueira, 1986) afirmam que os laços familiares permanentes são condicionados pela cultura, e não por necessidades biológicas. A família não é, portanto, algo biológico, algo natural ou dado, mas produto de diferentes formas históricas de organização entre os humanos. Premidos pelas necessidades materiais de sobrevivência e de reprodução da espécie, os humanos estabeleceram entre si diferentes formas de organização a fim de garantirem sua subsistência. As diferentes formas de organização dos grupos humanos, baseadas na divisão do trabalho social e sexual entre os seus membros, engendraram diferentes formas de relacionamento entre os mesmos, originando o que se denominou família (Engels, 1884/ 1964; Muraro, 1997; Schelsky, 1968).

Compreender as concepções de família na atualidade requer resgatar a historicidade das formas de organização familiares (Prado, 1991; Xavier, 1998). Descobertas arqueológicas (Bott, 1976; Muraro, 1997; Schelsky, 1968; Smith, 1973) revelaram que, no início da história da humanidade, as comunidades eram coletivistas, tribais e igualitárias, não havendo regras quanto ao acasalamento entre os membros. Os agrupamentos eram matrilineares, matrifocais e matrilocais, ou seja, os membros organizavam-se em pequenos grupos em torno da figura da mãe-mulher. A matrilinearidade era uma decorrência do desconhecimento da participação do homem (macho) na reprodução. Neste período, o acasalamento entre os membros ocorria dentro de um mesmo grupo, caracterizando a família consanguínea endogâmica. Posteriormente, surge a família exogâmica, na qual o casamento deveria ocorrer fora do grupo familiar. A função da exogamia seria a de manter a sobrevivência dos grupos. As alianças formadas pelos casamentos asseguravam a paz, o fortalecimento de redes de parentesco e a produção e a reprodução, necessários à sobrevivência. Uma das conseqüências da regra da exogamia foi o tabu do incesto, que prescreveu a interdição de relações sexuais entre pais e filhos e, logo após, entre irmãos (Engels, 1884/1964). A exogamia teria, portanto, um valor social de troca:

Certamente não é porque algum perigo biológico se ligue ao casamento consangüíneo, mas porque do casamento exógamo resulta um benefício social ... A lei da exogamia refere-se a valores - as mulheres valores por excelência ... sem as quais a vida não é possível . . . A proibição do incesto é menos uma regra que proíbe casar-se com a mãe, a irmã ou a filha do que uma regra que obriga a dar a outrem a mãe, a irmã ou a filha; é a regra do dom por excelência (Lèvi-Strauss, 1908/1982, p. 521-522).

A proibição do incesto é tema controverso. Alguns estudos falam da universalidade do tabu do incesto e de seu papel fundante na civilização (Lèvi-Strauss, 1908/1982). Outros, relativizam tal proposição, a partir do estudo de povos como os do Egito, da Pérsia, do Sião, da Birmânia e do Havaí, bem como entre os Queshuas (incas) e os fenícios, nos quais o incesto seria permitido e mesmo incentivado. Esses povos cultivavam a tradição de casamentos entre irmãos e irmãs e entre pais e filhos a fim de manter intacta a linhagem das casas reais (Schelsky, 1968). De toda forma, quaisquer que fossem as regras de exogamia, a família promíscua, característica das sociedades primitivas, tornou-se monogâmica ao longo da história em função de interesses político-econômicos associados ao surgimento da propriedade privada. O casamento monogâmico não foi fruto do amor sexual, uma vez que os casamentos eram arranjados por conveniência. A família monogâmica surgiu de condições econômicas, tendo por finalidade garantir herança aos filhos legítimos. Com a organização familiar monogâmica criou-se a divisão do trabalho e dos papéis sexuais e sociais. A valorização da virgindade e da fidelidade da mulher, bem como o controle sobre a sexualidade e sobre os corpos das mulheres, seriam tributários das formas patriarcais e monogâmicas de organização familiar (Engels, 1884/1964; Reich, 1966, 1933/1998; Schelsky, 1968).

As bases de nossa civilização estão fundadas na estrutura da família monogâmica patriarcal. Os primórdios dessa forma de organização foram encontrados na família romana. "Famulus quer dizer escravo doméstico, e família, o conjunto de escravos pertencentes a um mesmo homem", diz Engels (1884/1964, p.91). Com o tempo, o termo família passou a significar um grupo social cujo chefe mantinha sob seu poder a mulher, os filhos e certo número de escravos, com direito de vida e de morte sobre todos eles (Xavier, 1998).

Ariès (1981) distingue a família da linhagem nas organizações familiares da idade média. A família pode ser comparada à nossa família conjugal moderna, ou família nuclear monogâmica. Já a linhagem envolve todos os descendentes de um mesmo ancestral. Mais do que uma distinção, há uma oposição entre a família e a linhagem: os progressos de uma provocariam o enfraquecimento da outra, ao menos entre a nobreza. Na família feudal da Idade Média era a linhagem, e não o casamento, que estava no centro da vida familiar. A mulher era considerada como pertencente à linhagem do marido e quando este morria ela era excluída da linhagem. A família era do tipo extensa ou abrangente, ou seja, incluía outros parentes, amigos e vassalos. Os senhores feudais, preocupados com a legitimidade de seus filhos, exerciam forte controle sobre as mulheres, surgindo, nessa época, os "cintos de castidade", defendidos também pela igreja (Osório, 1996, 1997). A família conjugal moderna seria, portanto, conseqüência do enfraquecimento da linhagem e da família abrangente (Ariès, 1981).

Reis (1985) propôs um percurso histórico a fim de compreender a constituição da organização familiar contemporânea, predominantemente nuclear e burguesa. Segundo ele, na época feudal, a obediência à autoridade era altamente valorizada, sendo permitido o uso do castigo físico para garantir a ordem e a disciplina, quer na família, na escola ou no clero. A família aristocrata não atribuía valor algum à privacidade, à domesticidade, aos cuidados maternos ou às 
relações íntimas entre pais e filhos. A família camponesa, tal qual a família aristocrática, mantinha laços comunitários de dependência com a aldeia, a qual regulava a vida cotidiana através dos costumes e da tradição. Os rituais, como casamentos e enterros, envolviam a aldeia inteira. As crianças dependiam, principalmente, da comunidade e não dos pais, aprendendo a obedecer às normas sociais. Na medida em que as mulheres precisavam trabalhar, a mãe camponesa dividia a criação dos filhos com outras mulheres da comunidade. As crianças não eram o centro da vida familiar, nem o papel materno idealizado como viria a ser mais adiante. A sexualidade não era tão controlada e as necessidades sexuais das mulheres eram reconhecidas.

Já na constituição da família proletária, Reis (1985) identificou três diferentes fases. Na primeira, com a industrialização do século XIX, todos os membros da família trabalhavam conjuntamente para seu sustento. Neste contex to de precariedade e de opressão engendrados pelo capitalismo emergente, foi necessária a manutenção dos antigos laços comunitários de dependência e de apoio mútuo característicos das organizações feudais (Castel, 1998). Na segunda fase, na metade do século XIX, com a qualificação da classe operária, alguns burgueses começam a preocupar-se com a qualidade de vida de seus empregados. Com a melhoria de vida, a diferenciação dos papéis familiares na família proletária aproxima-se dos padrões da família burguesa, período no qual a mulher passa a ficar mais tempo em casa a fim de cuidar do lar e dos filhos. Na terceira fase, já no século XX, a família operária muda-se para o subúrbio, rompendo com os laços comunitários. Observa-se um reforço da autoridade paterna e um "aburguesamento" ideológico da classe operária (Reis, 1985).

A família burguesa, que teve seu berço na Europa, em meados do século XVIII, caracterizava-se pelo fechamento em si mesma (Castel, 1998). Esse isolamento das redes comunitárias e de parentesco gerou a dependência das crianças à figura da mãe na família burguesa, que dependiam dela para suprir suas necessidades materiais e de afeto. Ocasionou, ainda, a dependência da mulher ao marido, inclusive para seu sustento. Os corpos e a sexualidade das mulheres passam a ser regulados e controlados, servindo apenas à procriação, destituindo-lhes o direito ao prazer. Os padrões morais eram, entretanto, diferentes para homens, mulheres e crianças, permitindo-se e estimulando-se apenas a sexualidade masculina. A sexualidade infantil também passou a ser reprimida. O papel social de filho(a) prescrevia a submissão aos valores dos pais e, mais tarde, dos professores (Reich, 1966, 1933/1998; Reis, 1985).

No Brasil, identificamos também esta passagem do modelo patriarcal feudal ao modelo patriarcal nuclear burguês. A história da instituição familiar, no Brasil, tem como ponto de partida o modelo patriarcal, importado pela colonização e adaptado às condições sociais do Brasil de então, latifundiário e escravagista. O patriarca era o detentor das posses, não apenas de seu latifúndio, mas de sua família, de seus agregados e escravos. Nessa configuração, a mulher era considerada propriedade do patriarca. Mercadoria cambiável nos casamentos arranjados, depois de casada, cabia à mulher administrar a casa e servir ao marido como reprodutora (Canevacci, 1987; Figueira, 1986; Xavier, 1998). A mulher casada ou a jovem solteira que transgredisse os ditames patriarcais estavam sujeitas ao confinamento religioso. A tríade que sustentava a ideologia colonial era, portanto, o Patriarca, a Propriedade e a Igreja (Del Priore, 2001; D'Incao, 1989; Rocha, 2003).

As formas de organização econômica têm sido associadas às formas de organização social e familiar ao longo da história (Castel, 1998; Engels, 1884/1964; Muraro, 1997). A organização latifundiária, tal qual a feudal, assentava-se no protecionismo e na tutela do senhor em relação a seu grupo. Ao final da Idade Média, com o advento do capitalismo, o modelo patriarcal latifundiário brasileiro não mais servia aos interesses da burguesia. No novo modo de organização social capitalista, aboliu-se a tutela do senhor feudal, desvalorizaram-se as formas coletivas de produção e desfizeram-se as redes de solidariedade das familiares abrangentes. A dissociação dos espaços públicos e privados e o isolamento da família conjugal nuclear monogâmica da comunidade seriam, portanto, tributários da valorização do individualismo burguês capitalista. Na nova configuração familiar - a família nuclear burguesa - o homem deixava de ser o proprietário da família para ocupar o papel de pai provedor/mantenedor burguês da esposa e da prole. A mulher não mais era propriedade do marido, mas mãe educadora e protetora dos filhos, cuidadora do marido e do lar. Sob a égide do liberalismo, o casamento deixou de ter o caráter econômico de outrora para instituir-se como espaço de escolha entre sujeitos livres que aspiram à concretização do amor romântico (Del Priore, 200 1; D’Incao, 1989). Não mais baseada na necessidade de obediência natural da organização feudal hierárquica, a natureza passiva, cuidadora e frágil da mulher é agora invocada pelo discurso liberal para justificar o domínio masculino. Algumas teorias psicológicas, baseadas em concepções essencialistas de uma natureza feminina, naturalizaram papéis sexuais e sociais de homens e mulheres (ver Diamond, \& Quinby, 1998; Harding, 1987; Scott, 1986). A ciência positivista liberal, com suas disciplinas, entre elas a Psicologia, a Medicina e o Direito (Foucault, 1975/2002), teve papel fundamental na normatização do social (T. M. G. Fonseca, 1997). Inscrevese, nesse contexto, a construção de estereótipos sexistas, originando mitos, tais como o mito do amor materno, criticado por Badinter (1985). Legitimada agora pela ciência, a dominação masculina patriarcal foi, ao longo dos tempos, alterando suas configurações (Bedregal, 2002; Garretas, 2004).

Apesar das diversas transformações sociais que ocorreram nas últimas décadas nas famílias brasileiras (ver DeSouza, \& Baldwin, 2000; Rocha, 2003), a posição da mulher na família e na sociedade em geral, desde a colonização até hoje, mostra que a família patriarcal, rural, escravagista e poligâmica foi a matriz de nossa organização social (Saffioti, 1979, 2001). A gênese das atitudes autoritárias sobre a condição feminina também no meio urbano deve ser entendida em relação à dominação social que caracteriza o sistema patriarcal brasileiro (D'Ávila Neto, 1994). 
Pesquisas com famílias brasileiras demonstram que estereótipos sexistas ainda permanecem no imaginário social (Falcke \& Wagner, 2000; Spina, Morita, Camargo \& Cerveny, 1979; Szymanski, 1992, 1994, 1997, 1998; Wagner \& Bandeira, 1996; Zamberlan, Camargo \& Biasoli-Alves, 1997). A idéia de família na contemporaneidade parece ainda referir-se ao modelo da família monogâmica nuclear, burguesa e patriarcal descrito como o "modelo de família nuclear burguesa com conotação normativa” (Szymanski, 1997, p. 26). Este modelo de família baseia-se em relações de parentesco, estruturando-se em um contexto de relações estáveis marcada pela autoridade patriarcal do pai sobre a mãe e os filhos. A idealização desta forma de organização familiar seria, conforme Szymanski (1997, 1998), fruto da mediação institucional, que determina e legitima uma forma específica de interação familiar como a ideal. A diversidade e a pluralidade de formas de organização familiar que coexistem na atualidade, entre elas as famílias chefiadas por mulheres e as famílias com filhos de criação (Corrêa, 1982; C. Fonseca, 1989, 1995, 2001; Maluf, 1993) ficam, assim, invisibilizadas. A família nuclear burguesa baseada na autoridade patriarcal parece ser o modelo "normal" de família no imaginário social que, mesmo que não seja efetivamente vivida, é imaginada, pensada, idealizada. A autoridade na família "pensada" é exercida pelo pai e somente na ausência do mesmo a mãe poderá assumi-la. Na família "vivida", a autoridade evidencia uma inferioridade social em relação às mulheres e às crianças (Szymanski, 1994). Ainda que a participação dos homens nas famílias de nível sócio-econômico baixo seja bastante precária (uma vez que estas famílias geralmente constituem-se sem a presença do pai, devido à separação ou ao abandono) persiste o modelo do homem como provedor financeiro e de autoridade (Szymanski, 1992). A hegemonia do modelo idealizado da família nuclear e a dicotomia entre "família pensada e família vivida" (Szymanski, 1997, 1998), foram encontradas também nas concepções de meninas maltratadas que não mais vivem em suas famílias por estarem institucionalizadas (De Antoni \& Koller, 2000), e de crianças provenientes de famílias "reconstituídas" (Wagner \& Bandeira, 1996).

Pesquisa realizada por Falcke e Wagner (2000), com cinqüenta mulheres, mães e madrastas, encontrou um forte legado transgeracional relativo aos papéis de gênero. $\mathrm{Na}$ concepção de mãe das participantes, as mulheres são responsáveis pelo bem estar da família, sendo natural o papel de mãe na vida de uma mulher. Tal concepção correspondeu ao mito do amor materno incondicional, o que demonstra o poder e o valor que os mitos sociais têm na vida das pessoas. Spina, Morita, Camargo e Cerveny (1979) relatam a permanência da distinção, em famílias brasileiras, entre os papéis do pai e o da mãe na família nuclear contemporânea. Nestas famílias, as mulheres foram percebidas segundo valores tradicionais veiculados pela cultura acerca da divisão do trabalho na esfera doméstica conforme o sexo da pessoa. O papel assumido pela mãe relaciona-se à criação e ao cuidado dos filhos, enquanto o papel do pai, além de provedor econômico (embora a mãe também participe do sustento da família), associa-se à disciplina e à autoridade (Zamberlan, Camargo \& Biasoli-Alves, 1997). O casamento e a maternidade ainda são vistos como as principais fontes de realização feminina, sendo que às mulheres é atribuída a responsabilidade pela mediação das relações afetivas na família. $O$ fracasso nesta tarefa é geralmente vivenciado como culpa por esta mulher que, não acreditando na possibilidade de manter-se sozinha, e desejando manter a família unida, acaba por submeter-se, inclusive, a relações violentas (Cardoso, 1997a; Narvaz \& Koller, 2004b; Ravazzola, 1997, 1999).

Para Reich (1933/1998), a família é o principal fator de perpetuação do sistema social autoritário. Já Prado (1991) entende que a família apresenta aspectos positivos, enquanto núcleo afetivo, de apoio e de solidariedade entre seus membros. Para esta autora, não há, na história, uma sociedade que tenha vivido à margem de alguma forma de organização familiar. Mitchell (1987) também reconhece a necessidade de alguma forma de institucionalização das relações interpessoais. Para ela, a característica fundamental do atual sistema matrimonial e familiar é a organização monolítica, em que há uma só forma institucionalizada e legitimada de relações possíveis entre sexos e entre gerações. Essa rigidez é opressiva, causando sofrimento e discriminação aos indivíduos que não pertencem às formas consideradas legítimas de organização familiar. Nesse sentido,

Praticar a superação da atual família-fetiche significa derrotar os aspectos correspondentes do poder hereditário, que tem como motivação estrutural a transmissão dos bens e do privilégio e o direito de procriação que funda a autocracia da filiação contra a afinidade (Canevacci, 1987, p. 47).

Além da hegemonia do modelo legitimado de família em nossa sociedade, outro aspecto problemático refere-se à posição das crianças como propriedade dos pais (Narvaz \& Koller, 2004b) e à posição de menor poder das mulheres dentro da família (Saffioti, 1979, 2001). A relação dos pais com os filhos e entre homens e mulheres é marcada pela idéia de "diferenças intrínsecas" (Cooper, 1987), que são convertidas em desigualdades. Neste modelo, claramente hierárquico,

a identidade familiar é posicional. Todos são definidos a partir da sua posição de idade e de sexo. Há várias idéias em torno do que é 'certo’e 'errado', e há vários mecanismos sutis dentro e fora dos sujeitos para tentar suprimir ou controlar as várias formas de desvio de comportamento, pensamento ou desejo (Figueira, 1986, p. 15-16).

A partir do exposto, evidencia-a influência do patriarcado na estruturação da família brasileira na atualidade (D’Ávila Neto, 1994; Del Priore, 2001; Figueira, 1986; Saffioti, 1979; Xavier, 1998). O termo patriarcado foi introduzido na década de 70 por Kate Millet, para definir um sistema social e político de opressão e dominação dos homens sobre as mulheres (Werba, 2002). Entendido como modo universal ou, ao menos, predominante, geográfico e histórico, de relacionamentos, no patriarcado, a política sexual implica o fato de que os homens estabelecem as regras de poder e de controle social. O patriarcado é uma forma de organização 
regida por dois princípios básicos: (a) as mulheres estão hierarquicamente subordinadas aos homens; e, (b) os jovens estão hierarquicamente subordinados aos homens mais velhos (Millet, 1970). O patriarcado atribuiu um maior valor às atividades masculinas em detrimento das atividades femininas; legitimou o controle da sexualidade, dos corpos e da autonomia femininas; e, estabeleceu papéis sexuais e sociais nos quais o masculino sempre tem vantagens e prerrogativas (Castells, 1999; Diamond \& Quinby, 1998; Scott, 1986). O patriarcado não designa o poder do pai, mas dos homens, ou do masculino, enquanto categoria social (Goldner, 1985, 1988; Saffioti, 1979, 2001).

Estudos (ver Castro, \& Lavinas, 1992; Grossi, 2001; Scott, 1986; Werba, 2002) questionam a universalidade do patriarcado e sua associação à gênese das desigualdades e da violência contra as mulheres. Outros, entretanto, postulam a influência do patriarcado na organização da família pequeno-burguesa. A gênese, a manutenção e a reprodução das relações de poder abusivas características das famílias violentas têm sido relacionadas ao patriarcado (Castells, 1999; Goldner, 1985, 1988; Millet, 1970; Saffioti, 1979, 2001). A opressão do feminino mantém-se através da perpetuação da estrutura patriarcal pela reprodução dos valores e das normas ditadas pelo modelo de supremacia masculina, através de gerações, em diferentes culturas (Goodrich, Rampage, Ellman \& Halstead, 1990; Meneghel et al., 2003). Nas famílias violentas e incestuosas, é percebida uma forte adesão a modelos dominantes e estereotipados de gênero, com estruturas hierárquicas e distribuição rígida de papéis dentro da família. Estas estruturas familiares correspondem ao modelo da família patriarcal nuclear monogâmica e burguesa, que prima pela tradição, pela hierarquia e pela obediência das mulheres e das crianças ao homem-pai. Estes papéis sociais e sexuais são naturalizados e reproduzidos de geração em geração, favorecendo diversas formas de violência (Narvaz \& Koller, 2004a, 2004b), inclusive de incesto. A submissão constitui um componente fundamental do adestramento das mulheres à ordem social patriarcal (Bourdieu, 1999; Ravazzola, 1997, 1999; Strey, 1998), e à obediência das crianças e adolescentes ao ataque incestuoso do pai (Felipe, 1999). A obediência ao homem-pai, mesmo que abusivo, aparece como algo natural e esperado, resultado da desigual socialização de gênero ainda prevalente em nossa sociedade:

Entre os deveres sagrados da esposa está a obediência total ao marido ... que a usa para satisfazer seus desejos sexuais de acordo com suas necessidades ... Os elementos mais vulneráveis dentro da casa são as mulheres, as quais, por ignorância, medo e submissão à autoridade não ousam protestar. (Azevedo \& Guerra, 1989, p. 60).

Entendendo que a prevenção da violência supõe a desconstrução da dominação de gênero (Narvaz \& Koller, 2004a, 2004b), faz-se fundamental o compromisso com o desvelamento das formas de opressão a que têm sido submetidas, em especial, as mulheres e as meninas em nossa sociedade. Nesse sentido, investigar as concepções de família de uma mulher vítima de violência oportunizará esbo- çar intervenções que visem à problematização da hegemonia dos modelos de família existentes no imaginário social. Tal problematização pretende contribuir ao desvelamento e à desconstrução das relações abusivas que, naturalizadas pelos ditames patriarcais, são reproduzidas de geração em geração (Narvaz, 2002, 2003; Narvaz \& Koller, 2004a, 2004b) através da manutenção do modelo hegemônico de família normativa. Neste sentido, concordamos com MartínBaró (1997, p. 7) quando diz que:

O trabalho do psicólogo deve ser definido em função das circunstâncias concretas da população a que deve atender ... e pressupõe que ... recoloque seu conhecimento e sua práxis ao assumir a perspectiva das maiorias populares e opte por acompanhá-las no seu caminho histórico em direção à libertação.

\section{Método}

\section{Delineamento}

Este estudo utilizou o delineamento de Estudo de Caso Único (Yin, 1994). O Estudo de Caso é um método apropriado para investigar um fenômeno contemporâneo, dentro de um contex to de vida real, sendo adequada sua utilização quando o estudo se propõe a verificar uma teoria já existente. O delineamento do Estudo de Caso proposto por Yin (1994) envolve cinco componentes que estão interligados: (a) as questões de pesquisa; (b) as proposições; (c) a(s) unidades de análise; (d) a lógica que vincula os dados às proposições; e, (e) os critérios para a interpretação dos dados. A questão de pesquisa identifica o problema a ser investigado, enquanto as proposições focalizam uma área em especial a ser verificada em função do problema e dos objetivos da pesquisa. As unidades de análise emergem da questão inicial de pesquisa e das proposições teóricas a fim de delimitar as informações relevantes a serem coletadas e analisadas. O quarto e o quinto componentes do delineamento envolvem o processo de análise dos dados. De acordo com Yin (1994), há duas estratégias gerais para a análise dos dados: (a) Basear-se nas proposições teóricas; e, (b) Desenvolver uma descrição do caso. $\mathrm{Na}$ medida em que, segundo o autor, a primeira estratégia é a mais adequada para estudos de caso, optamos por essa estratégia no presente estudo. Assim, procuramos analisar o caso conforme as proposições que direcionaram a revisão teórica e a coleta dos dados.

\section{Participante}

Participou do estudo uma mulher, vítima de várias formas de violência, tanto em sua infância quanto em sua vida adulta, cujas filhas foram vítimas de incesto perpetrado pelo padrasto. Foram nomeadas, ficticiamente, as pessoas envolvidas no estudo para garantir a anonimidade dos processos descritos. A participante será denominada Iara; suas filhas serão chamadas Ana, a mais velha, e Vanessa, a caçula. O filho de Iara será chamado Gabriel. Os parceiros sexuais e conjugais, citados por Iara, com os quais manteve relacionamentos ao longo de sua história de vida serão chamados Paulo, Pedro, João, José e Aquiles. 
Iara é uma mulher, de 45 anos de idade, com baixo poder aquisitivo, residente de uma vila da periferia da cidade de Porto Alegre. De estatura mediana, Iara é filha de mãe índia; a tez morena e seus traços faciais revelam a miscigenação típica de sua descendência. Iara conviveu pouco tempo com seus pais biológicos na infância. A mãe, segundo ela, abandonou a família em função de outro homem quanto Iara tinha cerca de quatro anos de idade, embora visitasse os filhos de vez em quando. Iara e o irmão ficaram, então, aos cuidados do pai e da família paterna. Iara foi vítima de abuso sexual pelo tio paterno nessa época, quanto tinha cerca de quatro anos de idade. O pai de Iara, encontrando outra companheira, deixa a família paterna e os filhos. A mãe de Iara, sabendo disso, a leva para uma família substituta. $\mathrm{O}$ irmão permaneceu aos cuidados da mãe de Iara. Com cerca de 13 anos, Iara foge desta família substituta por sofrer diversas formas de violência, indo ao Juizado de Menores. Iara é entregue a outra família em São Paulo, a quem considera sua mãe adotiva, com quem mora até seus 17 anos, quando, segundo ela, é "devolvida" pela mãe adotiva para a mãe biológica. Nessa ocasião, aos 17 anos, Iara sofre assédio sexual de seu dentista. Iara engravida, pouco tempo depois, de um namorado, Paulo, ainda morando em São Paulo.

Desse relacionamento, com Paulo, Iara teve sua primeira filha, Ana. Iara e Paulo não se casaram legalmente, morando juntos durante apenas um ano. Segundo ela, o relacionamento não deu certo porque Paulo bebia e a agredia fisicamente. Após, Iara foi morar em Santa Maria, interior do Rio Grande do Sul, levando a filha Ana consigo. Relacionou-se com Pedro, com quem teve dois filhos, Gabriel e Vanessa. Segundo Iara, Pedro fazia brincadeiras de cunho sexual com a filha Ana, mas nunca soube se houve abuso sexual. Pedro também era abusador de álcool, de drogas e violento fisicamente com Iara. Pedro, conforme relato de Iara, vendo que esta não tinha condições econômicas de cuidar do filho Gabriel, então com dois anos de idade, entrega o menino para ser criado por sua irmã, em Porto Alegre.

Depois deste relacionamento, que durou cerca de dois anos, Iara veio morar na Grande Porto Alegre, a fim de ficar mais perto de seu filho. Teve um terceiro companheiro, João, com quem se casou legalmente, convivendo com ele durante cerca de quatro anos. Nesse período, a filha Ana ficava, segundo Iara, um pouco com ela, um pouco no internato, um pouco com sua mãe biológica e um pouco com sua mãe adotiva, em São Paulo. Iara relatou não nutrir sentimentos amorosos por João, que não a satisfazia sexualmente, mas lhe oferecia uma casa e uma família. Iara informou tratar muito mal este companheiro, sendo agressiva inclusive fisicamente com ele. João não era agressivo fisicamente com Iara, mas bebia e a agredia verbalmente, diz ela. Quando Iara discutia com João, voltava para Santa Maria e ficava lá um tempo com o companheiro anterior, Pedro, engravidando então da filha caçula, Vanessa. Retornando a Porto Alegre, voltou a morar com João que, mesmo sabendo não ser o pai biológico do bebê, assumiu a paternidade da menina, provendo alimentos à Vanessa até hoje. Enquanto morava com João, Iara conheceu seu quarto companheiro, José, com quem iniciou um relacionamento. Segundo Iara, José era um homem violento, ex-presidiário e abusava de álcool. José expulsou João de casa e passou a conviver com Iara e com suas filhas, Ana e Vanessa. José abusou sexualmente de Ana durante o período em que ela morou com a mãe, sendo agressivo física e emocionalmente tanto com Ana quanto com Iara. Iara e José estão separados há cerca de dois anos, período em que Iara começa a relacionar-se com Aquiles. O quinto e atual companheiro de Iara, Aquiles, é filho adotivo de José. Iara vive maritalmente com Aquiles há cerca de dois anos. Aquiles tem 23 anos de idade e trabalha com Iara no mercado informal. No momento, nenhum dos filhos reside com Iara. Em função do abuso cometido por José, Ana fugiu de casa aos 15 anos de idade e foi para um abrigo, não tendo mais contato pessoal com a mãe há cerca de dez anos. $\mathrm{O}$ filho, Gabriel, atualmente com 21 anos de idade, desde os dois anos foi criado pela madrinha e tia paterna, com quem reside até hoje em Porto Alegre. Ambos, Ana e Gabriel, não têm contato com a mãe, falando-se ocasionalmente apenas por telefone. Os irmãos também não têm contato entre si. A filha caçula, Vanessa, atualmente com 14 anos, sempre residiu com Iara. Entretanto, há cerca de um mês, devido à suspeita de abuso sexual que também Vanessa estaria sofrendo por parte de José, Vanessa foi morar com o pai adotivo, João. Vanessa e Iara continuam em contato. Iara, embora não tendo acreditado no abuso sexual de Ana, diz acreditar no relato de abuso de Vanessa, tomando providências legais de denúncia do abuso e de avaliação psicológica que estão sendo efetivadas no Centro de Referência ao Atendimento da Infância e Adolescência (CRAI), especializado no atendimento a situações de violência, sediado na instituição onde foi realizado o presente estudo.

\section{Instrumentos e Procedimentos}

Após a aprovação do projeto de pesquisa pelo Comitê de Ética da Universidade Federal do Rio Grande do Sul, foi feito contato com a instituição na qual foi realizada a investigação, um ambulatório de atendimento a famílias e vítimas de violência da rede pública de saúde de Porto Alegre. Foi solicitado à referida instituição o encaminhamento de possíveis participantes, ou seja, mulheres cujas filhas tivessem sido vítimas de incesto, perpetrado pelo pai ou padrasto, companheiro da mãe na ocasião do abuso. Uma vez encaminhada, a participante foi entrevistada individualmente. A entrevista foi gravada e posteriormente transcrita. Dada a extensão e a complexidade do estudo, foram realizadas duas entrevistas com Iara, totalizando cerca de cinco horas de duração. As entrevistas foram realizadas na própria instituição. Foi utilizada para a coleta dos dados uma entrevista semiestruturada, incluindo dados biodemográficos e questões referentes aos objetivos investigados, tais como, por exemplo: $o$ que é família, em sua concepção, e quem é sua família. 


\section{Questões Éticas}

Todo o processo de pesquisa foi realizado dentro dos Critérios da Ética na Pesquisa com Seres Humanos, conforme Resolução n. 196/96 do Conselho Nacional de Saúde (1996), sendo aprovada pelos Comitês de Ética da Universidade e da Instituição na qual foi realizada a investigação. O Termo de Consentimento Livre e Esclarecido foi lido e assinado pela participante. Dado o conteúdo mobilizador das entrevistas, a participante foi apoiada em todo o processo, sendo, inclusive, fornecidas informações sobre o acesso da participante aos sistemas de apoio legal, social e de saúde. A pesquisadora manteve contato com o referido Centro a fim de informar sobre locais de atendimento especializado em questões de violência sexual, uma vez expresso pela participante, durante as entrevistas, o desejo de prosseguir sendo acompanhada em atendimento psicológico.

\section{Resultados e Discussão}

A presente investigação constitui-se em um Estudo de Caso Único, cuja unidade de análise foi a história de uma família incestuosa ao longo de gerações. As informações foram coletadas de um único membro da família, ou seja, a mulher-mãe, vítima de várias formas de violência, da infância à atualidade, cujas filhas foram vítimas de incesto perpetrado pelo padrasto. A questão de pesquisa, o objetivo, a proposição teórica, a unidade e subunidades de análise desse estudo foram: (a) Questão de pesquisa: Qual a concepção de família de uma mulher-mãe de vítimas de incesto?; (b) Objetivo: Investigar a concepção de família de uma mulher-mãe de vítimas de incesto; (c) Proposição: A proposição teórica esboçada a partir da literatura investigada no presente estudo foi: A concepção de família de uma mulhermãe de vítimas de incesto corresponde à organização patriarcal, nuclear, monogâmica e burguesa; (d) Unidade de análise: a unidade de análise principal investigada, que emergiu da questão de pesquisa foi nomeada nesse estudo "Concepção de Família”. Os dados coletados foram analisados segundo a estratégia mais adequada de análise proposta por Yin (1994), ou seja, a partir da proposição teórica do estudo. A proposição teórica originou subunidades de análise para a categorização das respostas da participante, que foram: (a) Família Pensada e, (b) Família Vivida. As categorias identificadas foram descritas e exemplificadas por recortes de falas significativas, sendo discutidas de forma dinâmica e integrada à luz do referencial teórico estudado.

\section{Proposição}

A concepção de família de uma mulher-mãe de vítimas de incesto corresponde à organização patriarcal, nuclear, monogâmica e burguesa.

\section{Unidade de Análise - Concepção de Família}

Compreende as concepções e as vivências da participante sobre o que é uma família e sobre quem considera sua família. Incluem-se aqui duas subunidades: (a) Família Pensada (Szymanski, 1992, 1997, 1998), caracteriza-se pela definição do que é família para a participante do estudo; e, (b) Família Vivida (Szymanski, 1992, 1997, 1998), caracteriza-se pelas vivências de família descritas pela participante.

\section{Família pensada.}

A idéia de família expressa pela participante corresponde à configuração idealizada de família nuclear burguesa, modelo normativo de família (Szymanski, 1992, 1997, 1998) em nossa sociedade. Iara diz não saber o que é família, pois não vivenciou tal configuração, como demonstram as falas a seguir apresentadas.

Família... Ah, essa parte tá em falta... Na verdade [chora] acho que eu não sei, não sei o que é família ... Eu acho que não tenho família, porque família... família tem sido gato, cachorro, tem sido a família ... Eu acredito que não foi uma família, por que minha mãe, bem dizer, desmoronou nós, né. A minha família já veio desmoronada já desde ali, né... Eu tinha quatro anos, meu irmão, dois anos... Ela foi embora com uma pessoa e fico nós pra trás ... Ela [mãe] vivia com meu pai, não era casada no papel ..

O desejo de ter uma família, uma casa e os filhos perto de si evidenciam o valor e a concepção de família idealizada por Iara.

Eu não gostava dele [João, o terceiro companheiro], mas eu queria ter uma casa, ter uma família ... Com esse eu casei no papel mesmo ... Quando o Pedro, o pai do guri me tirou ele, eu sofri muito [chora] por que eu queria muito ter um filho comigo ... Já tinha ficado sem a guria mais velha e agora sem o guri, aí resolvi que ia engravidar de novo, e armei uma armadilha pra ele [risos] e engravidei da minha mais nova, a Vanessa.

Outras concepções de família que se referem às famílias de criação também são identificadas em suas falas.

Minha mãe me deu para pra ser criada com eles [família substituta], pra ser criada como filha ... Aí eles [o Juizado de Menores] passaram eu pra outra família, a de São Paulo ... O meu filho também foi tirado de perto de mim, quem cria é a madrinha ... O pai do meu filho [Pedro, o segundo companheiro], ele tirou o guri de mim porque eu não tinha condições de criar, né, não tinha trabalho. Aí ele deu pra irmã dele criar, ela era viúva e não tinha filhos, cria ele até hoje... A minha filha mais velha, a Ana, eu não criei, bem dizer ela, quem criou mais foi a avó dela lá de São Paulo ...

A proximidade e o afeto na criação e na adoção são valorizados por Iara em sua concepção de família, em contraste com a idealização da família nuclear consangüínea.

O meu atual companheiro [Aquiles] é filho adotivo do meu ex-companheiro [José], mas não tem nada de sangue, nada a ver ... É filho adotivo ... Adotivo, bem dizer, só de nome, porque na verdade quem criou só foi a ex-mulher dele, ela que criou ... Era um pai só de visita ... Esse outro [o terceiro companheiro, João] que assumiu a minha filha mais nova, a Vanessa, não é o pai biológico dela, mas assumiu ela como pai .. . Ele não é o pai verdadeiro dela, mas foi quem deu o nome e quem criou e é o pai que ela ama.

\section{Família vivida.}

Diversas configurações familiares foram vivenciadas ao longo do tempo pela participante do estudo. Foram identifi- 
cados quatro núcleos distintos, quais sejam: família de origem, família substituta, mãe adotiva e família atual. Em suas falas, destacam-se elementos relativos à consangüinidade, ao parentesco, à criação e à proximidade e ao apoio afetivo em suas vivências de família.

\section{Família de origem.}

Compreende o grupo de pessoas com as quais Iara tem relações consangüíneas e de parentesco.

Eu na verdade não fui criada com a minha mãe, nem com o meu pai, né ... Fiquei com o meu pai, no caso, porque quando ela deixô eu, ela deixo com o meu pai, desde os quatro anos, na casa do meu avô, do meu tio, era tudo junto, daí ele saiu, quando ele foi à luta de conseguir outra mulher também ... Eu acho que eu fui vê mesmo eles depois dos 17 anos é que eu fui... me aproximando da... bem dizê família, que eu digo, né. Assim, familiares, né. Familiares que eu fui vê, os tios, coisa assim . . .

\section{Família substituta.}

Compreende o grupo de pessoas com as quais Iara foi criada em substituição à família de origem. Devido aos abusos vivenciados, Iara não considera esta sua família.

Aí como eu falei eu tava com uns quatro anos de idade mais ou menos e a minha mãe me pegou pra leva pra essa outra família, pra essa família que me criô até os quinze anos mais ou menos, mas eles me tratavam como uma escrava, um tipo de escravidão. Não me tratavam bem. Essa eu não considero família ... Como eu achava que eu apanhava muito eu peguei um dia e fugi, né? Fugi e fui num Juizado de Menores.

\section{Mãe adotiva.}

Refere-se à pessoa por quem Iara foi criada e que, apesar de não ter legalizado a adoção, é percebida como mãe adotiva.

Aí eles passaram eu pra outra família, a de São Paulo, aí que eu fui morar com essa que eu chamo ela de mãe. Morei com ela uns anos. Essa senhora tava procurando justo uma menina pra trabalhar na casa dela. Ela diz criar, mas é pra morar na casa dela, ela queria uma menina pequena ... Ela não quis me adotar porque eu já era grande, mas resolveu experimentar e disse: 'Quando tu tiver uma certa idade eu vou te devolver pra tua mãe legítima.' E quando eu tinha 17 anos foi quando ela me devolveu para minha mãe legítima. Fiquei até aos 17 anos e depois ela mesma foi no juiz e me passou pra minha mãe de novo. Essa, a de São Paulo que eu considero minha mãe. Mas faz tempo que eu não falo com ela... faz uns 14 anos que eu não vejo ela... Ela cuidou da mais velha [a filha] pra mim quando eu levei ela pra lá, por causa do abuso.

\section{Família atual.}

A família atual é definida por Iara pelas pessoas com as quais têm relações consangüíneas e de parentesco.

Minha família atualmente, pra mim tem sido só minha pequena [a filha Vanessa], agora no momento, né. Ela que me dá força, que vem tomar conta de mim quando eu preciso. Eu tenho outro filho também, de vinte anos ... Mas ele não me liga ... A minha filha [Vanessa] tá morando com o pai dela, por causa do abuso, agora que ela não tá comigo, mas ela me liga pra mim . . . Eu tenho outra filha, a Ana, a mais velha, mas ela tá morando longe agora e me liga só de vez em quando... Na família os únicos que agora tem é nós dois [ela e o irmão]. Minha mãe, não tenho mais. Só tem um irmão, só que mora no interior de J.C. O pai também já é falecido. Meu pai, eu fiquei muitos anos sem vê ele. Muito, muito, muitos anos sem vê ele... Os outros são parente, passou, não se visitam ... Não tem mais mãe, não tem mais pai ... Então ficou só nós, meu irmão e meus sobrinhos, minha cunhada também, eles sempre procuram ser uma família pra mim ...

O companheiro é mencionado como a pessoa com quem Iara mora, ficando ambígua a forma como percebe esse vínculo, se considerado ou não como sua família. Não explicita claramente que o considera de sua família. Destaca-se a entonação conferida ao termo "mora" em sua fala.

"Eu tenho uma pessoa que mora comigo... O meu atual companheiro ..."

A análise das respostas à entrevista, dadas por Iara, indicou que sua concepção de família corresponde ao modelo idealizado de família nuclear burguesa patriarcal, definida pelas relações consangüíneas e de parentesco composta por pai, mãe e filhos biológicos (Szymanski, 1992, 1997). A proposição de nosso estudo, qual seja, a de que a concepção de família de uma mulher vítima de violência corresponde à organização patriarcal, nuclear, monogâmica e burguesa, encontra, assim, sustentação na análise destes dados. Inicialmente, a participante diz não saber o que é família e não ter família, porque a sua família já veio "desmoronada" pelo abandono da mãe. Uma vez que não vivenciou o modelo idealizado, Iara percebe-se como não tendo família. A concepção e a vivência de família aparecem quase indissociáveis em suas falas. Entretanto, a configuração a que Iara se refere como não sabendo o que é, por não ter efetivamente vivido, diz respeito à família nuclear burguesa com conotação normativa. Tal idéia de família, segundo Szymanski (1992, 1997), ainda parece ser o modelo idealizado de família na contemporaneidade. Embora praticamente não tenha vivenciado o modelo idealizado e normativo de família nuclear nem em sua infância nem na vida adulta, o desejo de ter uma família e uma casa, com os filhos e filhas perto de si foi evidente em sua fala. Iara conta ter-se submetido a conviver com um companheiro que não amava para ter acesso a esse bem simbólico, ou seja, a família. Iara refere-se, por várias vezes, ao abandono da mãe biológica, que não lhe deu carinho nem amor quando pequena, bem como à falta de convivência com o pai. A valorização da relação com o irmão e com a família deste, referindo-se à cunhada e às sobrinhas que a procuram e que tentam ser uma família para ela e o desejo de restabelecer as relações, ao menos por telefone, com os filhos que lhe "foram tirados", evidenciam a valorização da família consangüínea. A definição de família passa, portanto, pelas noções de consangüinidade e de parentesco, característicos do modelo de família burguesa, patriarcal, monogâmica normativa (Szymanski, 1992, 1997). 
Iara refere-se às vivências de família a partir de oposições, marcadas por adjetivos como "biológica", significando legítima, em oposição à “adotiva” ou "de criação". Apesar dessa oposição, percebe-se a valorização da proximidade, do apoio, do carinho e do cuidado ao definir quem considera sua família. Se, num primeiro momento, Iara dizia não saber o que é família, ou não ter tido família, paulatinamente seu discurso vai desvelando outras formas de organização familiar, as famílias adotivas ou famílias de criação, que foram vividas, quer por ela própria, quer pelas filhas e pelo filho. Desconsidera, por vezes, a consangüinidade e o parentesco, bem como a legitimidade de alguém que "é adotivo só no nome, porque não criou”, ao referir-se a José, pai do atual companheiro de Iara, por exemplo. Esses aspectos são observados também em relação às duas famílias substitutas com as quais Iara conviveu, referindo-se à família de São Paulo como a "verdadeira família" ou a "verdadeira mãe" que, mesmo sem ter adotado Iara legalmente, é vivenciada como "mãe adotiva". A família a quem Iara foi dada pela mãe para ser criada, percebida como abusiva, não é considerada família, expressando claramente que nunca mais a procurou. $\mathrm{Na}$ família atual, valoriza a adoção pelo padrasto (João) da filha mais nova Vanessa, que, mesmo não sendo o pai biológico da menina, a adotou, e "é o pai que ela ama", com quem está morando atualmente, diz Iara. Já José (pai de Aquiles, atual companheiro de Iara) é desvalorizado em seu papel de pai uma vez que não criou, nem conviveu com o filho, "sendo pai de visita", diz ela. Percebe-se, nesse sentido, o valor atribuído ao cuidado e à criação como marcas importantes em sua concepção de família. Por outro lado, a criação de seu filho pela madrinha, bem como a criação da filha mais velha Ana, e a sua própria criação pela mãe adotiva de São Paulo são vivenciadas com certa ambivalência. Se, por um lado, suas falas sugerem a valorização dessas formas de organização familiar, especialmente se permeadas por relações de afeto e cuidado, percebe-se também certa tristeza e sentimentos de perda "pelos filhos que lhe foram tirados" e "por não ter tido uma família e não ter sido criada por sua mãe biológi$c a$. Nestes momentos, chora na entrevista. Tais emoções parecem denunciar o desejo e a impotência/incompetência autoconfessa de Iara de manter sua família unida, bem como de não ter vivenciado a configuração de família legitimada pela ordem patriarcal burguesa, que regula as concepções de família normativa (Szymanski, 1992).

Diversas configurações familiares coexistem na atualidade com o modelo hegemônico da família nuclear patriarcal burguesa, tais como famílias chefiadas por mulheres sozinhas e famílias de criação. Entretanto, tais configurações e práticas têm sido invisibilizadas ou desvalorizadas (Corrêa, 1982; C. Fonseca, 1989, 1995, 2001; Maluf, 1993). Sabe-se que a competência das famílias não depende de sua estrutura ou de sua configuração, mas da qualidade das relações estabelecidas entre seus membros (Costa, Penso \& Féres-Carneiro, 1992). As vivências de família de Iara correspondem às configurações contra-hegemônicas ao modelo de família normativa. Embora valorizadas, as configurações vivenciadas não aparecem como modelos reconheci- dos e legítimos de família. Dada a idealização da família nuclear em nossa sociedade, parece ser esse o modelo pensado e desejado de família encontrados no relato de Iara.

Para Gomes, Deslades, Veiga, Bhering e Santos (2002), diversas mudanças têm sido observadas na composição da família brasileira contemporânea dos diferentes segmentos sociais. No entanto, as famílias que não são organizadas de forma nuclear, com alternância de parceiros da mulher-mãe, são estigmatizadas como desajustadas ou desestruturadas, como se lhes fosse atribuído um estatuto menor do que o modelo idealizado de família nuclear. Este aspecto pode ser encontrado quando Iara percebe sua família como "desmoronada", quando destaca que o pai e a mãe "não eram casados no papel', ao mesmo tempo em que valoriza "ter casado no papel' com João, o terceiro companheiro. Também a ambigüidade de Iara ao referir-se ao atual companheiro, Aquiles, como pertencendo à sua família atual ou não, sugere a influência na normatização do casal monogâmico na prescrição da concepção de família. Aquiles é o companheiro que mora com ela, ao passo que João foi o marido com quem "casou no papel mesmo”. Evidencia-se, assim, a influência das relações patriarcais na organização da família pequeno-burguesa contemporânea (Castells, 1999; Goldner,1985, 1988; Millet, 1970), ou, ao menos, em sua representação e no desejo de vivê-la. Neste caso, parece ser esta a concepção de "verdadeira família", em contraste com o a "família vivida”, percebida por Iara como "família desmoronada". Tais aspectos confirmam os achados relativos à dissociação entre "família vivida e à família pensada” (Szymanski, 1997, 1998), em que o modelo hegemônico de família nuclear é encontrado mesmo no imaginário de meninas maltratadas, como Iara (De Antoni \& Koller, 2000). Verificam-se tensões nas falas de Iara, que oscilam entre a valorização da família normativa e a valorização dos vínculos de afeto expressos no cuidado e na criação, quaisquer que sejam as configurações familiares em que estejam inscritos. As distinções entre família vivida e família pensada relacionam-se, na história de vida de Iara, à questão das adoções e dos filhos de criação. Na medida em que tanto a mãe de Iara quanto ela própria necessitavam trabalhar, e não contavam com o apoio dos companheiros, recorreram a outras mulheres e à família extensa para o cuidado dos filhos. Essa prática de circulação de crianças foi encontrada em vários estudos com famílias brasileiras (Corrêa, 1982; C. Fonseca, 1989, 1995, 200 1; Maluf, 1993). Uma vez capturada pelo discurso patriarcal burguês, que prescreve à mulher a reclusão no espaço doméstico e sua dedicação à casa e aos filhos (D'Incao, 1989; Reich, 1966; Reis, 1985), tal prática é percebida por Iara de forma negativa. Tanto a mãe de Iara é vista como abandonante, responsável pelo "desmoronamento" da família, quanto ela própria parece culpar-se e sofrer por não ter permanecido junto de seus filhos. Recorrer à rede de parentesco, como forma de apoio para sua maternidade solteira, ao invés de ser percebido como fator de proteção e de solidariedade, foi vivenciado por Iara como incapacidade e com sentimento de perda.

Ao mesmo tempo em que se vê capturada pelo discurso patriarcal burguês, que normatiza e legitima uma forma 
monolítica de família como válida (Mitchell, 1987), Iara também valoriza o cuidado, o afeto e a criação presentes em sua história de vida. As famílias vividas por Iara são configurações encontradas nas famílias brasileiras há séculos, tais como as famílias chefiadas por mulheres e as famílias com filhos de criação. No entanto, o estigma atribuído aos indivíduos que vivem em configurações familiares que fogem aos ditames patriarcais é opressivo e fonte de sofrimento psíquico (Canevacci, 1987; Figueira, 1986; Mitchell, 1987). Mulheres e crianças, influenciadas pelos ditames patriarcais, e movidas pelo desejo de ter uma família e de mantê-la unida, submetem-se a relações violentas (Cardoso, 1997a, 1997b), inclusive ao incesto (Felipe, 1999). Esses valores, reproduzidos através de gerações, confirmam achados relativos à transmissão transgeracional da violência (Carrasco, 2003; McCloskey \& Bailey, 2000; Narvaz, 2002, 2003; Narvaz \& Koller, 2004a). Essa reprodução de valores aprendidos não se baseia, como erroneamente pode ser interpretada (ver Guareschi, Comunello, Nardini, \& Hoenisch, 2004), em concepções deterministas. Trata-se, isto sim, de padrões construídos no cotidiano concreto de relações no seio da família e que, pela socialização de seus membros, são transmitidos de geração em geração (Narvaz $\&$ Koller, 2004b), o que se confirmou na presente investigação. Uma vez que "homens e mulheres reproduzem a ordem social e cultural na qual se engendram, podendo reelaborála e recriá-la dentro de contex tos e conjunturas específicas" (T. M. G. Fonseca, 2000, p. 18), em cada repetição, há a possibilidade de novas reconfigurações das experiências vividas, que podem ser invertidas e subvertidas.

\section{Considerações Finais}

Procuramos demonstrar a correspondência dos ditames patriarcais na concepção de família de uma mulher-mãe, vítima de várias formas de violência em sua história de vida, cujas filhas foram vítimas de incesto. O modelo patriarcal de família influenciou a concepção de família da participante do nosso estudo, embora não tenha sido o modelo efetivamente vivido de família em sua história de vida. Achados de Szymanski (1992, 1994, 1997, 1998) sobre a dissociação entre família vivida e família pensada, bem como a pluralidade das formas de organização das famílias brasileiras que coexiste com o modelo patriarcal (Corrêa, 1982; C. Fonseca, 1989, 1995, 2001; Maluf, 1993) foram encontradas em nossa investigação. Tal pluralidade, precisa, no entanto, ser legitimada pela ordem social e científica (Mitchell, 1987), uma vez que o desejo de viver o modelo hegemônico de família evidenciou-se, no caso analisado, como fator de submissão a relações violentas. Outras pesquisas relativas ao tema são recomendadas, envolvendo a percepção de vários membros de uma mesma família, uma vez que o presente estudo baseou-se em apenas um caso e na percepção de um único membro, a mulher-mãe da família incestuosa pesquisada. A inclusão de outras variáveis como idade, sexo/gênero, classe social, raça/etnia e diferentes configurações familiares em novas investigações sobre a concepção de família são necessárias.

\section{Referências}

Ariès, P. (1981). História social da criança e da família. Rio de Janeiro, RJ: LTC.

Azevedo, M., \& Guerra, V. (1989). Violência doméstica contra crianças e adolescentes. São Paulo, SP: Cultrix.

Badinter, E. (1985). Um amor conquistado: O mito do amor materno. Rio de Janeiro, RJ: Nova Fronteira.

Bedregal, X. (2002). Desafios del feminismo frente al nuevo desorden patriarcal. Retirado em 15 mar. 2003, de http:// www.creatividadfeminista.org/articulos/ximena_desafios.htm.

Bott, E. (1976). Família e rede social. Rio de Janeiro, RJ: Francisco Alves.

Bourdieu, P. (1999). A dominação masculina. Rio de Janeiro, RJ: Bertrand Brasil.

Canevacci, M. (1987). Dialética da família. Gênese, estrutura e dinâmica de uma instituição repressiva. São Paulo, SP: Brasiliense.

Cardoso, N. M. (1997a). A socialização do gênero feminino e suas implicações na violência conjugal em relação às mulheres. In A.V. Zanella, M. J. Siqueira, L. A. Lulhier \& S. I. Molon (Eds.), Psicologia e práticas sociais (pp. 280-292). Porto Alegre, RS: ABRAPSO-SUL

Cardoso, N. M. (1997b). Mulher e maus-tratos. In M. Strey (Ed.), Mulher: Estudos de gênero (pp. 127- 138). São Leopoldo, RS: Editora da Universidade do Vale do Rio dos Sinos.

Carrasco, L. K. (2003). A mulher vítima de violência conjugal: Uma perspectiva transgeracional. Tese de Doutorado não-publicada, Programa de Pós-Graduação em Psicologia, Pontifícia Universidade Católica do Rio Grande do Sul, Porto Alegre, RS.

Castel, R. (1998). As metamorfoses da questão social: Uma crônica do salário. Petrópolis, RJ: Vozes.

Castells, M. (1999). O poder da identidade. São Paulo, SP: Paz e Terra.

Castro, M., \& Lavinas, L. (1992). Do feminino ao gênero: A construção de um objeto. In A. Costa \& C. Bruschini (Eds.), Uma questão de gênero (pp. 216-251). São Paulo, SP: Rosa dos Tempos.

Conselho Nacional de Saúde (1996). Resolução 196 de outubro de 1996. Brasília, DF: Ministério da Saúde.

Cooper, D. (1987). A morte da família. São Paulo, SP: Martins Fontes.

Corrêa, M. (1982). Repensando a família patriarcal brasileira. Notas para o estudo das formas de organização familiar no Brasil. In M. Corrêa (Ed.), Colcha de retalhos: Estudos sobre a família no Brasil (pp. 13-38). São Paulo, SP: Brasiliense.

Costa, L. F., Penso, M. A., \& Féres-Carneiro, T. (1992). Reorganizações familiares: As possibilidades de saúde a partir da separação conjugal. Psicologia: Teoria \&̊ Pesquisa, 8, 495-503.

D’Ávila Neto, M. I. (1994). O autoritarismo e a mulher: O jogo da dominação macho-fémea no Brasil. Rio de Janeiro, RJ: Artes \& Contos.

De Antoni, C., \& Koller, S. H. (2000). A visão de família entre as adolescentes que sofreram violência intrafamiliar. Estudos de Psicologia, 5(2), 347-381.

Del Priore, M. (2001). História das mulheres do Brasil (2. ed.). São Paulo, SP: Contexto.

DeSouza, E., \& Baldwin, J. (2000). A construção social dos papéis sexuais femininos. Psicologia: Reflexão e Crítica, 13(3), 23-34.

Diamond, I., \& Quinby, L. (1998). Feminism \& Foucault: Reflections on resistance. Retirado em 10 mar. 2004, de http:// thefoucaultiano.co.ukmm. 
D’Incao, M. A. (1989). O amor romântico e a família burguesa. In M. A. D’Incao (Ed.), Amor e família no Brasil (pp. 57-71). São Paulo, SP: Contexto.

Engels, F. (1964). El origem de la familia, de la propiedad privada e del Estado. Buenos Aires, Argentina: Clariedad. (Original publicado em 1884)

Falcke, D., \& Wagner, A. (2000). Mães e madrastas: Mitos sociais e autoconceito. Estudos de Psicologia, 5(2), 421-441.

Felipe, S. (1999, Abril). Cumplicidade e violência. Trabalho apresentado ao Congresso Internacional de Família e Violência, Florianópolis, SC.

Figueira, S. (1986). Uma nova família? Rio de Janeiro, RJ: Zahar. Fonseca, C. (1989). Pais e filhos na família popular. In M. A. D’Incao (Ed.), Amor e família no Brasil (pp. 95-128). São Paulo, SP: Contexto.

Fonseca, C. (1995). Caminhos da adoção. São Paulo, SP: Cortez.

Fonseca, C. (2001). Família, fofoca e honra: Etnografia de relações de gênero e violência em grupos populares. Porto Alegre, RS: Editora da Universidade Federal do Rio Grande do Sul.

Fonseca, T. M. G. (1997). Psicologia e relações de gênero: O gênero da ciência psicológica. In A.V.Zanella, M. J. Siqueira, L. A. Lulhier \& S. I. Molon (Eds.), Psicologia e práticas sociais (pp. 317-32 1). Porto Alegre, RS: ABRAPSO.

Fonseca, T. M. G. (2000). Gênero, subjetividade e trabalho. Petrópolis, RJ: Vozes.

Foucault, M. (2002). Vigiar e punir: Nascimento da prisão (25. ed.). Petrópolis, RJ: Vozes. (Original publicado em 1975)

Garretas, M. M. R. (2004). Nombrar el mundo en femenino: Pensamiento de las mujeres y teoría feministas. Retirado em 15 mar. 2004, de http:// www.creatividadfeminista.org/articulos/ milagros_genero 1 .

Goldner, V. (1985). Warning: Family therapy may be hazardous to your health. The Family Therapy Networker, 9(6), 18-23.

Goldner, V. (1988). The treatment of violence and victimization in intimate relationships. Family Process, 37, 263-286.

Gomes, R; Deslades, S. F.; Veiga, M. M.; Bhering, C., \& Santos, J. F. (2002). Por que as crianças são maltratadas? Explicações para a prática de maus-tratos infantis na literatura. Cadernos de Saúde Pública, 18(3), 707-714.

Goodrich, T. J., Rampage, C., Ellman, B., \& Halstead, K. (1990). Terapia feminista da família. Porto Alegre, RS: Artes Médicas.

Grossi, P. K. (2001). Por uma nova ótica e uma nova ética na abordagem da violência contra mulheres nas relações conjugais. In P. K. Grossi \& G. C. Werba (Eds.), Violências e gênero: Coisas que a gente não gostaria de saber (pp. 19-45). Porto Alegre, RS: Editora da Pontifícia Universidade Católica do Rio Grande do Sul.

Guareschi, N.; Comunello, L. N.; Nardini, M., \& Hoenisch, J. C. (2004). Problematizando as práticas psicológicas no modo de entender a violência. In M. N. Strey, M. Azambuja \& F. Jaeger (Eds.), Violência, gênero e políticas públicas: Vol. 2. Gênero e contemporaneidade (pp. 177-194). Porto Alegre, RS: Editora da Pontifícia Universidade Católica do Rio Grande do Sul.

Lèvi-Strauss, C. (1982). As estruturas elementares do parentesco. Petrópolis, RJ: Vozes. (Original publicado em 1908)

McCloskey, L. E., \& Bailey, J. (2000). The intergenerational transmission of risk for child sexual abuse. Journal of Interpersonal Violence, 15(10), 1019-1035.

Maluf, S. (1993). Encontros noturnos: Bruxas e bruxarias na Lagoa da Conceição. Rio de Janeiro, RJ: Rosa dos Tempos.
Martín-Baró, I. (1997). O papel do psicólogo. Estudos de Psicologia, 2(1), 7-27.

Meneghel, S., Barbiani, R., Steffen, H., Wunder, A. P., Dalla Roza, M., Rotermund, J., Brito, S., \& Korndorfer, C. (2003). Impacto de grupos de mulheres em situação de vulnerabilidade de gênero. Cadernos de Saúde Pública, 19(4), 15-22.

Millet, K. (1970). Sexual politics. New York: Doubleday \& Company. Mitchell, J. (1987). La rivoluzione piú lunga. In M. Canevacci (Ed.), Dialética da família. Gênese, estrutura e dinâmica de uma instituição repressiva (pp. 272-273). São Paulo, SP: Brasiliense.

Muraro, R. M. (1997). A mulher no terceiro milênio: Uma história da mulher através dos tempos e suas perspectivas para o futuro (4. ed.). Rio de Janeiro, RJ: Record.

Narvaz, M. (2002). A transmissão transgeracional da violência. Insight, $11(18), 17-22$.

Narvaz, M. (2003). Quem são as mães das vítimas de incesto? Nova Perspectiva Sistêmica, 21, 40-44.

Narvaz, M., \& Koller, S. H. (2004a). Famílias, gêneros e violências: Desvelando as tramas da transmissão transgeracional da violência de gênero. In M. Strey, M. P. R. de Azambuja \& F. P. Jaeger (Eds.), Violência, gênero e políticas públicas: Vol. 2. Gênero e contemporaneidade (pp. 149-176). Porto Alegre, RS: Editora da Pontifícia Universidade Católica do Rio Grande do Sul.

Narvaz, M., \& Koller, S. H. (2004b). Por uma pedagogia nãoviolenta: A questão do castigo físico como forma de disciplinamento. Revista Teoria e Prática da Educação, 7(1), 28-35.

Osório, L. C. (1996). Família hoje. Porto Alegre, RS: Artes Médicas.

Osório, L. C. (1997). A família como grupo primordial. In D. E. Zimermann \& L. C. Osório (Eds.), Como trabalhamos com grupos (pp. 49-59). Porto Alegre, RS: Artes Médicas.

Prado, D. (1991). O que é família? São Paulo, SP: Brasiliense.

Ravazzola, M. C. (1997). Violencia familiar: El abuso relacional como un ataque a los derechos humanos. Sistemas Familiares, 23, 29-42.

Ravazzola, M. C. (1999). Historias infames: Los maltratos en las relaciones. Buenos Aires, Argentina: Paidós.

Reich, W. (1966). A revolução sexual. São Paulo, SP: Círculo do Livro.

Reich, W. (1998). Psicologia de massas do fascismo (2. ed.). São Paulo, SP: Martins Fontes. (Original publicado em 1933)

Reis, J. R. T. (1985). Família, emoção e ideologia. In S. Lane \& W. Codo (Eds.), Psicologia Social: O homem em movimento (3. ed., pp. 99-124). São Paulo, SP: Brasiliense.

Rocha, J. C. C. (2003). Mulher, família e trabalho numa abordagem sócio-histórica. Monografia não-publicada, Curso de Formação de Psicólogos, Universidade Estácio de Sá, Rio de Janeiro, RJ.

Saffioti, H. (1979). A mulher na sociedade de classes: Mitos e realidade. Rio de Janeiro, RJ: Rocco.

Saffioti, H. (2001). Contribuições feministas para o estudo da violência de gênero. Cadernos Pagu, 16, 115-136.

Schelsky, H. (1968). Sociologia da sexualidade. Rio de Janeiro, RJ: Paz e Terra.

Scott, J. (1986). Gender: A useful category of historical analysis. The American Historical Review, 91(5), 1053-1101.

Smith, R. T. (1973). The matrifocal family. In J. Godoy (Ed.), The caracter of kinship. New York: Cambridge University Press.

Spina, A., Morita, A., Camargo, C., \& Cerveny, C. (1979). Papéis familiares em famílias de periferia. Cadernos PUC, 15, 90-101.

Strey, M. N. (1998). Gênero. In M. G. C. Jacques, M. N. Strey, N. 
M.G. Bernardes, P. Guareschi, S.A. Carlos \& T. M. G. Fonseca (Eds.), Psicologia social contemporânea: Livro-texto (pp. 181198). Petrópolis, RJ: Vozes.

Szymanski, H. (1992). Trabalhando com famílias. Caderno de Ação, 1, 1-39.

Szymanski, H. (1994). Educação para família: Uma proposta de trabalho preventivo. Revista Brasileira de Crescimento e Desenvolvimento Humano, 4, 34-39.

Szymanski, H. (1997). Teorias e "teorias" de famílias. In M. C. B. Carvalho (Ed.), A família contemporânea em debate (pp. 23-27). São Paulo, SP: Editora da Pontifícia Universidade Católica de São Paulo.

Szymanski, H. (1998). Significados de família. In G. Loch \& M. A Yunes (Eds.), A família que se pensa e a família que se vive (pp. 9-17). Rio Grande, RS: Fundação Universidade Federal do Rio Grande.

Wagner, A., \& Bandeira, D. R. (1996). O desenho da família: Um estudo sobre adolescentes e famílias originais e reconstituídas. In R. M. Macedo (Ed.), Coletâneas da ANPEPP: Família e comunidade (pp.115-126). São Paulo, SP: Press Grafic.
Werba, G. C. (2002, Agosto). Quero ficar no teu corpo... Violência contra o corpo da mulher. Simpósio conduzido durante a I Jornada Gênero e Corpo, PUCRS, Porto Alegre.

Xavier, E. (1998). Declínio do patriarcado: A família no imaginário feminino. Rio de Janeiro, RJ: Rosa dos Tempos.

Yin, R. (1994). Case study research: Design and methods. London: Sage.

Zamberlan, M. A. T., Camargo, F., \& Biasoli-Alves, Z. M. M. (1997). Interações na família: Revisões empíricas. In M. A. T. Zamberlan \& Z. M. M. Biasoli-Alves (Eds.), Interações familiares: Teoria, pesquisa e subsídios à intervenção (pp. 39-57). Londrina, PR: Universidade Estadual de Londrina.

Recebido: 22/02/2005

$1^{a}$ revisão: $30 / 03 / 2005$

$2^{a}$ revisãa: $22 / 12 / 2005$

Aceite final: 24/01/2006 